\title{
THE DEMOGRAPHIC PROCESSES AND \\ THE REGIONAL DISPARITIES IN BULGARIA
}

DOI: http://dx.doi.org/10.18509/GBP.2020.47

UDC: 314.116(497.2)"1890/2018"

\author{
Atanas Dermendzhiev \\ Martin Doykov \\ Department of Geography, Faculty of History, "St. Cyril and St. Methodius" \\ University of Veliko Tarnovo, Bulgaria
}

\begin{abstract}
After the Second World War the population of Bulgaria has been constantly increasing, because of the industrialization of the country that stimulated its urbanization and led to improvement of the living conditions. The number of population was expected to reach nine million people in the late 1980's. However, with the fall of communism and the democratic changes, the people appeared to be in new conditions, providing the possibilities for free internal migration in the territory of the country, as well as relatively free emigration. In the years of transition from planned to market economy, the situation was not very favorable for normal reproduction of the population too.

The situation didn't change in the beginning of XXI century. With the increasing rate of emigration (mainly of labor force) after the accession of the country to the EU, and the decreasing of birth rate, the people were also getting concentrated in large cities, where they could find better jobs, causing significant regional demographic, as well as economic disparities. This made some researchers describe the situation as demographic catastrophe, questioning the future development of the country...

The research studies different aspects of the demographic changes that took place in Bulgaria in the last decades, including increase rate, migration, ageing and dynamics of the population and its distribution among the different regions. Different research methods have been used, such as situation and comparative analyses, complex approach, statistical methods and others.
\end{abstract}

Keywords: demography, regional disparities, trends, socio-economic development

\section{INTRODUCTION}

The balanced demographic development of the population of Bulgaria is national and social priority of great significance, requiring maximum concentration of the efforts and implementation of active, purposeful and consecutive governmental policy, as well as unification and coordination of the operation of authorities, institutions and structures of civil society on central, regional and local level.

The platform for realization of demographic policy in Bulgaria in strategic and operative aspect is laid on a systematic, wide intersectoral ground and is based on the principles for horizontal influence and application of integrated approach. The National Demographic Strategy is a basic document, which formulates the priority directions and tasks in the sphere of demographic policy, aimed at slowing the speed of decreasing of the number of population with tendency for its stabilization in long-term aspect and the providing of high quality of the human capital, including people with their health status, erudition, qualification, abilities and skills. 
In the conditions of demographic transition from a rate of increasing of the population to a rate of its stabilization (decreasing) and ageing, the National Demographic Strategy is built on the concept for balance of the population, in which leading is the idea for increasing of the living standard, the quality of life and well-being of every Bulgarian citizen and of every Bulgarian family, as well as guaranty for conditions for optimal development of the nation in its entirety and unity.

Object of the demographic strategy is the whole population of the Republic of Bulgaria. The strategy considers the peculiarities and specific necessities, typical for each one of the three main phases of human life cycle (youth, active age and pension age). Each of the age groups takes certain place and has its role in socio-economic relations, as well as in the relations among generations. The strategy for demographic development is the national answer to the demographic changes, in front of which stays Europe, revealed in even lower levels of birth rates, ageing of population and intensive migration processes. The main elements of the National Demographic Strategy are formulated in correspondence with the concepts of the demographic policy of the European Union.

\section{THE DEMOGRAPHIC DEVELOPMENT IN BULGARIA}

The change in the number of population reflects its dynamics. From the times of the origin of the Bulgarian state until nowadays the number of population has been constantly changing, which is due to a number of factors - cultural-historical, socio-economic, military-political, territorial range. In 2017 the population of Bulgaria is 7050000 people, which makes $1,4 \%$ of the population of EU.

Table 1. Official censuses of the population in Bulgaria (1880 - 2011)

\begin{tabular}{|c|c|}
\hline Year & Number of population \\
\hline 1880 & $2008000^{4}$ \\
\hline 1887 & 3154000 \\
\hline 1892 & 3311000 \\
\hline 1900 & 3744000 \\
\hline 1905 & 4036000 \\
\hline 1910 & 4338000 \\
\hline 1920 & 4847000 \\
\hline 1926 & 5529000 \\
\hline 1934 & 6078000 \\
\hline 1946 & 7029000 \\
\hline 1956 & 7629000 \\
\hline 1965 & 8228000 \\
\hline 1975 & 8728000 \\
\hline 1985 & 8949000 \\
\hline 1992 & 8487000 \\
\hline 2001 & 7933000 \\
\hline 2011 & 7365000 \\
\hline
\end{tabular}

The changes in the number of population reflect also its density. From the end of World War II, when the territory of Bulgaria gets constant size, it is largest at the end of the 1980's (Table 1) [5]. The territories with low density of the population face a number of demographic, social and economic problems.

\footnotetext{
${ }^{4}$ The data is about the Principality of Bulgaria.
} 
After the middle of XX century gradual decreasing of the birth rate has been observed. The reasons for this are connected with the changes of cultural traditions of the Bulgarian society and the place of women in it. With the socio-economic changes after 1989 the birth rate continued its decreasing. In 2018 the crude birth rate is 8,9\%o. In the regions with higher birth rate the population has better reproduction capabilities because of the younger age structure (Eastern Rhodopes, Ludogorie, Eastern Balkan Mountains). In some of these regions there are more Bulgarian Turks and Romas, and that's why this value is higher.

For the period between 2007 and 2018 in Bulgaria were born 840746 children, or 170 062 children average per year. Until 2009 there was a gradual increasing of the indicator, but during the following two years there was a significant decreasing (Figure 1) with about 5000 per year. In the period after 2012 the trend of decreasing of the number of live births remained, and in the end of the period that has been studied, when the indicator reached its lowest value, 13152 less children were born, compared to the beginning of the period in 2007 [5]. This represents a decrease of $17 \%$.

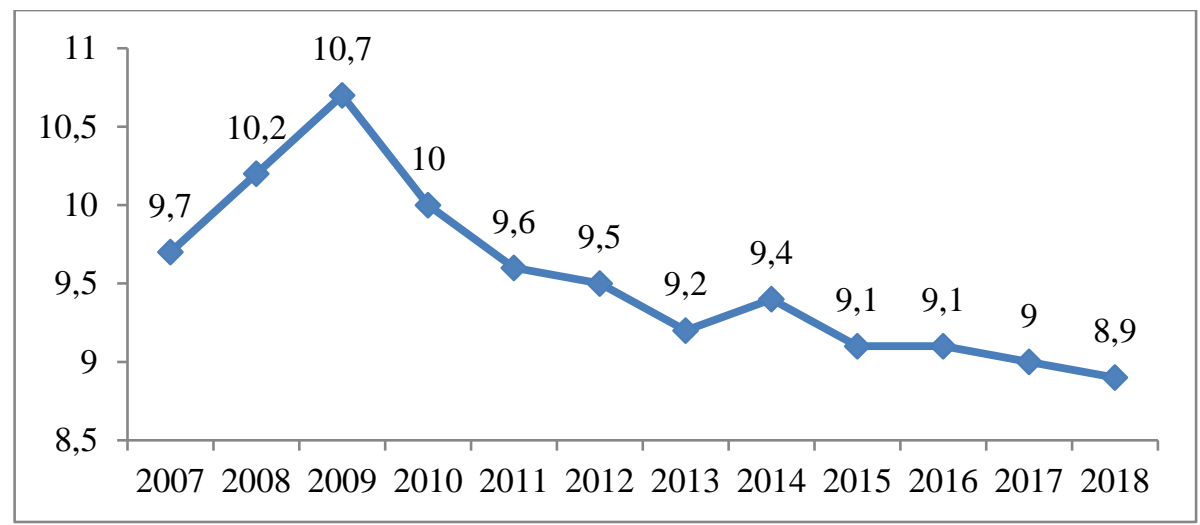

Figure 1. Birth rate in Bulgaria (\%), 2007-2018

From the Liberation until the middle of the 1960's the mortality rate quickly decreased. This was consequence of the improved living conditions and the young age structure of the population. After this the mortality rate was constantly growing, which was due to the decreasing birth rate and the ageing of population.

For the period between 2007 and 2018 there were 1308610 deaths in the country, or 109 050 average per year. However, the difference between the number of deaths in the first and in the last year of the period is just 4478 . We cannot state that there are some trends in the mortality during the period [5].

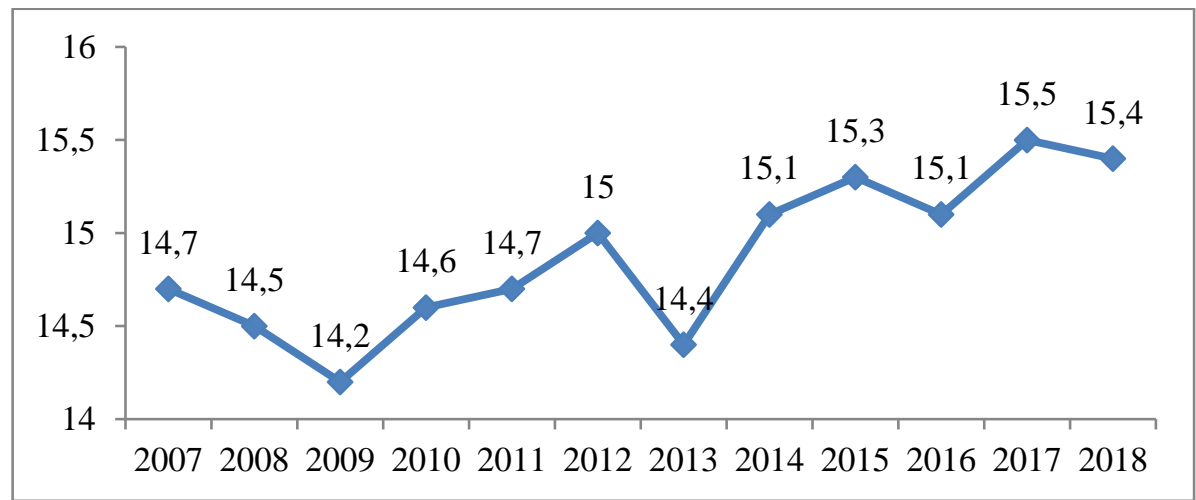

Figure 2. Death-rate in Bulgaria (\%o), 2007-2018 
In the beginning of the period between 2007 and 2009 there is a decrease of the mortality rate, while after that the changes are dynamical, but with increasing trend (Figure 2). Especially high is its value in the regions with worse age structure. In villages the mortality rate is higher than in towns.

The demographic situation in Bulgaria is revealed partly also by the coefficient of infant mortality rate, which in 2007 is $9,2 \%$ and after a general decrease until nowadays it reaches 5,8\%o in 2018. It is higher in villages than in towns, which can be explained by the access to health services [5].

According to the data about the birth and mortality rates, the natural increase rate of the population has been gradually decreasing and after 1990 it has negative value (Table 2).

Table 2. Natural increase of the population in the period $1890-2017$ [5]

\begin{tabular}{|c|c|c|c|}
\hline Year & Birth rate (\%o) & Mortality rate (\%o) & Natural increase rate (\%o) \\
\hline 1890 & 34,9 & 21,0 & 13,9 \\
\hline 1900 & 42,2 & 22,5 & 19,7 \\
\hline 1920 & 39,9 & 21,4 & 18,5 \\
\hline 1934 & 30,1 & 14,1 & 16,0 \\
\hline 1946 & 25,6 & 13,7 & 11,9 \\
\hline 1965 & 15,3 & 8,1 & 7,2 \\
\hline 1985 & 13,3 & 12,0 & 1,3 \\
\hline 1992 & 10,4 & 12,6 & $-2,2$ \\
\hline 1997 & 7,7 & 14,7 & $-7,0$ \\
\hline 2010 & 10,0 & 14,6 & $-4,6$ \\
\hline 2017 & 9,0 & 15,5 & $-6,5$ \\
\hline
\end{tabular}

For the period 2007-2018 having 840746 born and 1420746 deaths, the natural increase in the country is -579791 people, which means that it loses 48315 people average per year due to the natural increase rate. During the first three years of the period the natural increase rate is growing and it reaches its most favorable value of $-3,5 \%$, after which it decreases until the absolute minimum of $-6,5 \%$ in 2018 (Figure 3).

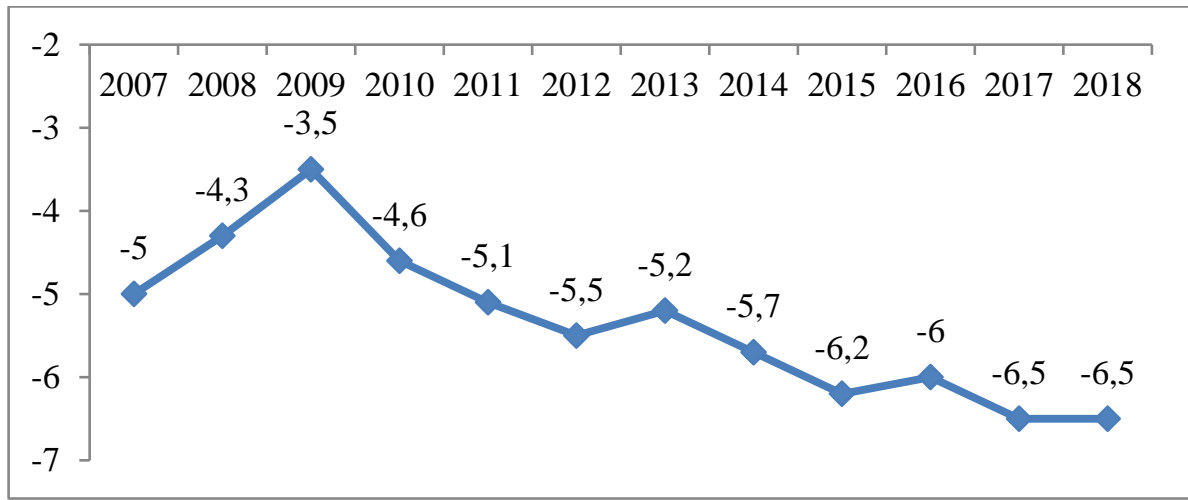

Figure 3. Natural increase rate in Bulgaria (\%), 2007-2018

The natural increase coefficient in all administrative districts of Bulgaria is negative. It varies between $-1,3 \%$ in the District of Sofia-city to $-16,2 \%$ in the District of Vidin.

If the present natural increase rate remains the same, according to the prognoses of the National Statistical Institute of Bulgaria (NSI), in 2030 the population of Bulgaria will be about 6,5 million people. Until the middle of the century it will be less than $6 \mathrm{mln}$. people and less than $5 \mathrm{mln}$. people in 2075 [6]. 
The processes of industrialization and urbanization after the Second World War led to active migration from villages to towns. Thus there was increasing of the urban population, while the villages depopulated [2]. After the democratic changes the population of the main attractive centers (especially Sofia) increased very quickly.

Internal migrations are important for the demographic characteristics of the population. They lead to qualitative and quantitative changes of the demographic resources. The qualitative are connected with the changes of number and natural movement, and the quantitative - with changes in the structure and composition of the population.

In 2017 in the internal migrations participated 113000 people. According to the directions they are: "town - town" (42\%); "village - town" (24\%); "town - village" (22\%); "village - village" (12\%). The internal migrations in 2018 include 109810 people and $42 \%$ of them are in "town-town" direction. $17 \%$ of all migrants settled in the district of Sofia-capital.

In 1989 about 350000 Bulgarian Turks were forced to migrate to Turkey. After the beginning of the democratic changes many Bulgarians migrated to the states of Western Europe, USA, Canada and Australia. This was due to the socio-economic problems of the transition period (from planned to market economy), connected with decreasing of the living standard. Mainly young, educated and qualified people emigrated. The accession of Bulgaria to the EU in 2007 stimulated these processes. However, within the context of the globalizing world, the studies of the Bulgarian population cannot be regarded just as negative trends. During the last years, as a consequence of the worse military-political situation in the Near East, a number of Arabians settled in the country.

More and more often we witness negative attitude to refugees, seeking asylum in Bulgaria. That provokes the realization of different initiatives, most frequently organized by nongovernmental structures. Example of that is "The school as a refuge" initiative, whose main purpose is to help for the integration of refugees in the Bulgarian society. Their representative visits secondary schools with the offer to be discussed and solved the problems of the reception of refugees-students for particular time ( $2-3$ months). The condition is during this time they have to live for one week with families of Bulgarian students.

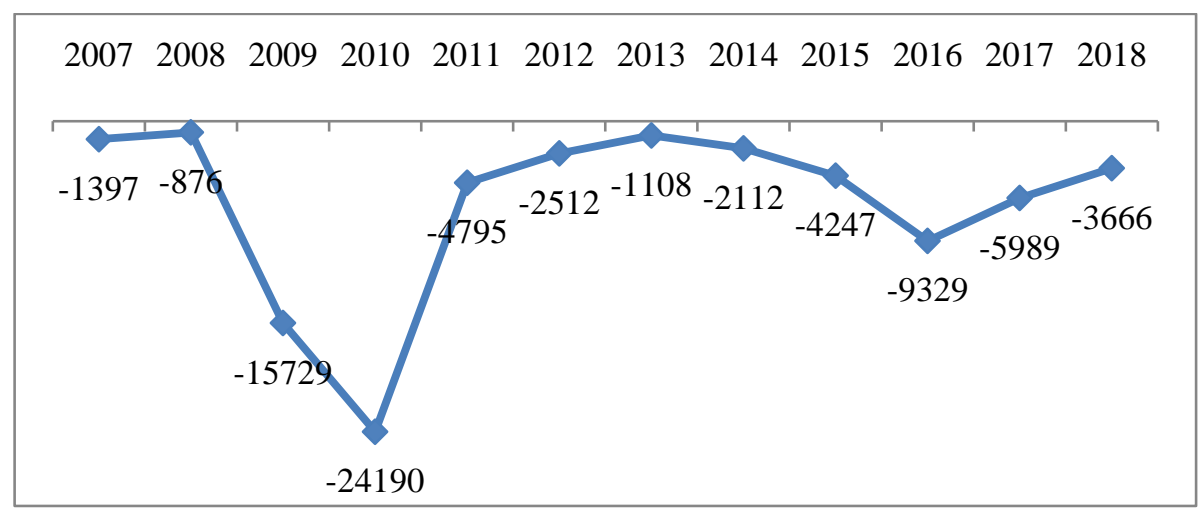

Figure 4. Net migration in Bulgaria (number), 2007-2018

After 2007 much more emigrants than immigrants can be observed in two periods (Figure 4). Between 2009 and 2011 as a consequence of the migration Bulgaria lost 44714 people altogether. In the period 2015-2017 the country lost 19565 people. With about 31586 emigrants in 2017, and 25597 immigrants, the net migration is negative (-5989 people), and the net migration rate is $-0,9 \%$. In the other years the indicators were very similar, 
but in all years the number of emigrants was larger than the number of immigrants. The net migration for the whole period was -75950 people. The general trend is of significant increasing of the migration rate. The country has been losing average 6329 people per year due to the migration rate [5]. 59\% of the emigrants left the country during the first period (2009-2011).

The migration rate of the population is intensive, but the difference between the number of immigrants and emigrants in most of the years is not large and as a final result it does not influence significantly the general migration rate in the country and the number of population. Or at least according to the official statistics...

The main demographic and social problems, connected with the structure of population, are the demographic ageing, depopulation and unemployment. The unemployment during the last years is decreasing, but it is still reason for the poverty of part of the population and for the migration.

The process of the ageing of population continues. In 2018 the group of the up to 15-yearold children is about $1 \mathrm{mln}$. people or $14,4 \%$ of the whole population. Around 1,5 mln. people or $21,3 \%$ of the population are over 65 -year-old. This process is more intensive among women, which is normal with a view to their longer life expectancy. More than $25 \%$ is the population of the group over 65-year-old in North-Western (the districts of Vidin and Montana), North-Central (the districts of Pleven, Lovech and Gabrovo) and some of the districts at the western state border (Kyustendil and Pernik). Lowest are these values in the large centers (the districts of Sofia-capital, Varna, Burgas). Highest percentage is the young population in the districts of Sliven $(18,5 \%)$ and Burgas, and lowest - in the districts of Smolyan $(11,5 \%)$ and Gabrovo [3].

The coefficient of age dependency is constantly increasing and in the period 2007-2018 it has increased by $11,2 \%$. The group of over 65 -years-old people has increased with $8,2 \%$, while the under 15-years-old group has increased with just 3\% [5].

According to NSI in 2017 the group of over 65-year-old compared to the young people (0-14-year-old) in the country is $148 \%$, and the correlation of the over 65 -year-old to the group of the 15-64-year-old is $32 \%$ [4].

The ageing of population leads to the increasing of its average age, which in the end of 2018 reached 43,8 years, while in villages it is 46,4 years.

Another important demographic factor is the average life expectancy. Socio-economic and ecological conditions for living exert influence on it. The average life expectancy for men is lower than for women. For the period 2015-2017 it is 74,8 years (71,3 years for men and 78,4 years for women) [6].

There is a stable trend of depopulation of the rural regions in Bulgaria. The settlement network in the country consists of 5256 settlements, 257 of which are towns. The urban population is $73,3 \%$. 34\% of the population lives in the six largest cities. In more than 570 villages live up to 9 people or nobody lives in them. The number of settlements without population is highest in the districts of Gabrovo (64) and Veliko Tarnovo (55).

Large are the disproportions of the distribution of population in the country, and between Northern and Southern Bulgaria in particular. The South-Western region, where the capital city is situated, has $30 \%$ of the population of the country. Most sparsely populated are the three regions in Northern Bulgaria, which has $35,1 \%$ of the all population. The districts of Vidin, Montana and Vratsa have largest decreasing of population compared to the previous year [7]. 


\section{CONCLUSION}

In conclusion we should state that the number of live births and the coefficient of birth rate are still decreasing. At the same time the coefficient of mortality rate reaches its highest values during the last two years. Positive trend is the decreasing of the infant mortality rate. The population continues its decreasing and in the same time it is ageing. The most urgent measures and policies, which should be undertaken in demographic and socio-economic aspect, should be in the following directions [1]:

- Development of regional demographic policies with focus on the falling behind parts of the country and considering the peculiarities of the separate regions, their demographic trends, the socio-economic situation, the ethno-psychology and attitude of the population, the resources and traditions;

- Establishment of much closer relation between business and higher education, mainly of master's degree level, which is also much more flexible in respect to the changes of the curricula, provision of practices and so on;

- Development of "silver" or "digital" economy, orientated to the over 50-year-old people with the clear purpose their active life to be extended, as well as their participation in the productive processes;

- Financial stimulation and tax concessions for families with two and more children, but with obligatory additional condition for minimal educational threshold for the parents (after secondary education!);

- Financial and social provision for deserted parents, a type of parenting which is something common in the contemporary developed societies;

- Active actions until the desegregation of the Roma population.

The imbalance in the distribution of population is increasing, which also influences the structure of the settlement network in the country. The largest towns continue to attract population which influences positively their demographic profile, and negatively the territories where the population has lower living standard.

This supposes actualization of the national demographic policy which should focus on stimulation of the birth rate by providing paid maternity leave, children allowances, free medicines for children and pregnant women, medical treatment of sterility, financing of assisted reproduction (in vitro procedures) and others.

Bulgaria is in a difficult demographic situation, but it is not hopeless, especially considering the unique natural and climatic resources and traditions of the country. Changing of the point of view, of the attitudes and the focus, as well as a lot of purposeful work are needed in order the negative demographic trends to be transformed into positive in the near future.

\section{REFERENCES}

[1] G. Bardarov \& N. Ilieva. Horizon 2030. Demographic Trends in Bulgaria, Sofia, Bulgaria, pp. 1-34, 2018.

[2] G. Geshev. The depopulation of rural areas in Bulgaria, Problems of Geography, Bulgaria, vol. 4, pp. 25-38, 1990.

[3] B. Kazakov. The demographic situation in southeastern Bulgaria according to the demographic situation, Problems of Geography, Bulgaria, vol. 1-2, 59-67, 2015.

[4] V. Stoyanova \& N. Karlezhova. Population and Demographic Processes 2018, Bulgaria, 2019. Accessible at: https://www.nsi.bg/sites/default/files/files/publications/DMGR2018.pdf 
[5] NSI - Demographic and social statistics. Accessible at: https://infostat.nsi.bg/infostat/pages/module.jsf?x_2=3

[6] NSI - Population - demography, migration and prognoses. Accessible at: https://www.nsi.bg/bg/content/2920/naselenie-demografia-migratsia-i-prognozi

[7] NSI - Population and demographic prognoses. Accessible at: https://www.nsi.bg/sites/default/files/files/pressreleases/Population2018_en_ZG7X53J.pdf 